\title{
Siliceous subglacial deposits: archives of subglacial processes during the Last Glacial Maximum
}

\section{Article}

Cite this article: Siman-Tov S, Blackburn T, Hallet B, Coble MA, Brodsky EE (2021). Siliceous subglacial deposits: archives of subglacial processes during the Last Glacial Maximum. Journal of Glaciology 67(266), 977-984. https://doi.org/10.1017/jog.2021.42

Received: 16 August 2020

Revised: 26 March 2021

Accepted: 29 March 2021

First published online: 12 May 2021

\section{Key words:}

extraterrestrial glaciology; glacier geology; mountain glaciers; subglacial precipitates and ice regelation; subglacial processes

\section{Author for correspondence:}

Shalev Siman-Tov, E-mail: shalevst@gsi.gov.il
Shalev Siman-Tov ${ }^{1}$, Terrence Blackburn², Bernard Hallet ${ }^{3}$, Matthew A. Coble ${ }^{4,5}$ and Emily E. Brodsky²

${ }^{1}$ Geological Survey of Israel, 32 Yesha'ayahu Leibowitz, Jerusalem 9692100, Israel; ${ }^{2}$ Department of Earth and Planetary Sciences, University of California, Santa Cruz, 1156 High Street., CA 95064, USA; ${ }^{3}$ Quaternary Research Center, University of Washington, Seattle, WA, USA; ${ }^{4}$ Stanford University, 367 Panama Street, Room 93, Stanford, CA, USA and ${ }^{5}$ School of Geography, Environment and Earth Sciences, Victoria University of Wellington, Wellington 6140 , New Zealand

\section{Abstract}

We report detailed chemical and isotopic data from a subglacial siliceous deposit on andesitic bedrock recently exposed by glacier retreat. Whereas a single, $<1 \mu \mathrm{m}$, Si-rich layer covers the highly polished bedrock on the up-glacier (stoss) surfaces, distinct, lithified deposits commonly occur at the lee of small bedrock protuberances, on a scale $<0.1$ meter. The deposit is millimeters in thickness and consists of laminae tens to hundreds microns thick that differ from one another in color, rock-fragment abundance and chemical composition. Ca-rich laminae that are sufficiently enriched in uranium $(\sim 2-50 \mathrm{ppm})$ to permit U-series isotopic analysis suggest that the subglacial deposit formed 10-20 ka, much earlier than previously assumed. We conclude that (1) the siliceous deposit persisted for at least 10000 years despite the intervening erosion and weathering, (2) distinct episodes of formation due to significant changes in hydrology and water chemistry are recorded in the deposit, and (3) a siliceous slurry may have existed at the ice-rock interface and influenced the local friction. This work reinforces earlier findings that subglacial chemical deposits can form and persist on geologic time scales and may have implications for the role of the cryosphere in the Earth's geochemical cycles and climate system.

\section{Introduction}

Exposed bedrock near retreating glaciers commonly exhibits features indicative of subglacial chemical processes. The most prominent examples occur on carbonate bedrock, in the form of well-developed, thin surface deposits that result from subglacial precipitation of $\mathrm{CaCO}_{3}$ in close association with small undulations (wavelengths generally smaller than $0.1 \mathrm{~m}$ ) in the bed topography (e.g. Hallet, 1976; Sharp and others, 1990; Carter and others, 2003; Liu and others, 2005; Thomazo and others, 2017). Considerable field and geochemical evidence suggests that subglacial chemical activity is driven by water flow and freezing/melting in a microscopic film at the ice-bedrock interface (i.e. regelation; Fig. 1); these processes are sustained by basal ice motion past topographic highs in the glacier bed (e.g. $\mathrm{Ng}$ and Hallet, 2002). On the stoss (up-glacier) side, ice melts producing very dilute, chemically aggressive water, i.e. highly under-saturated water with respect to the carbonate deposits, that dissolves the bed. The refreezing of this water on the lee side elevates its solute concentration to the point that $\mathrm{CaCO}_{3}$ precipitates due to the solute exclusion by ice growth (cryo-concentration). This description accounts well for the morphology, mineralogy and geochemistry of the subglacial $\mathrm{CaCO}_{3}$ precipitates, as well as observed spatial pattern of dissolution and precipitation (Hubbard and Hubbard, 1998).

By comparison, little is known about subglacial siliceous deposits, and yet they may provide longer archives of past ice masses and basal conditions than the more easily weathered subglacial carbonate deposits that generally survive for only a few decades once exposed to the atmosphere by ice recession (Ford and others, 1970). Moreover, they should have broad implications for diverse research fields involving cryospheric processes ranging from the global silicon cycle on Earth (e.g. Hawkings and others, 2018) and to the formation of silica and amorphous coatings on Mars (e.g. Smith and others, 2018).

Herein, we provide new isotopic data and describe the micron- to nano-scale chemical variation of mm-thick siliceous laminated deposit on abraded andesitic bedrock recently exposed by glacier retreat on Mt. Rainier, WA, USA. We explore the clues about subglacial processes encrypted in this deposit, leveraging recent findings about widespread microscopic subglacial silica-rich coatings on abraded granite (Siman-Tov and others, 2017; Blackburn and others, 2019).

\section{Study area and methods}

The studied sample was collected from the surface of an outcrop of glacially eroded bedrock in a valley largely mantled with rock debris $1.8 \mathrm{~km}$ down-valley from Paradise Glacier (in 2019), 


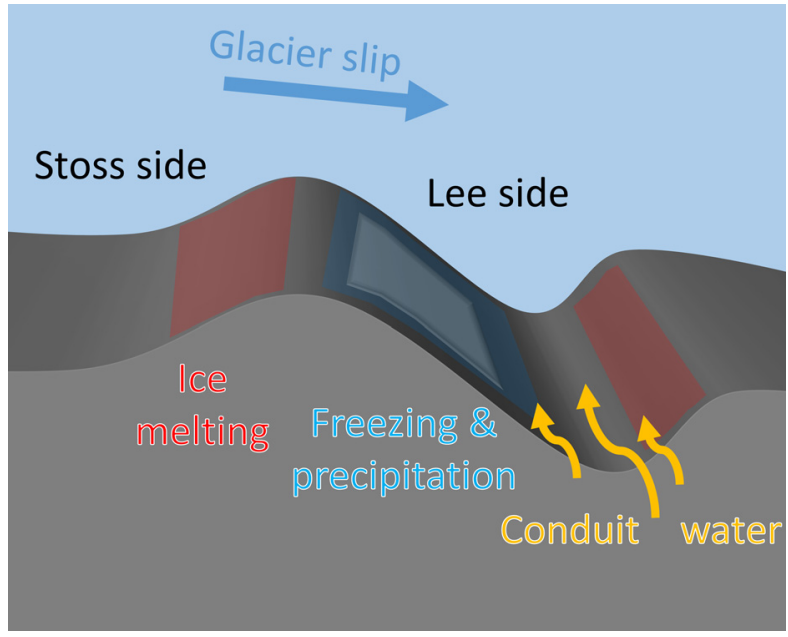

Fig. 1. Conceptual model of processes under a temperate glacier. As a glacier slides to the right (wide arrow) over small $(<0.1 \mathrm{~m})$ glacier bed undulations, ice melts along stoss surfaces (red), producing relatively pure water and forcing rocks in the basal ice to abrade the bed; the resulting water flows down pressure gradients to nearby lee surfaces (blue) where it refreezes. The sliding-induced freezing excludes ions in the water, causing solute enrichment in a thin film water at the ice-rock interface that can exceed saturation, leading to precipitation (deposit marked by a light grey layer on the lee side). At times, the composition of the water in the film can change when it connects and mixes with meltwater flowing through the system of larger conduits under the glacier (yellow arrows).

on the southeastern flank of Mount Rainier, Washington, USA (Fig. 2a). It is very similar to a sample described previously by Hallet (1975) (Fig. S1) that was collected nearby (within tens of meters), and the lee-side deposit is representative of others that are common on outcrops in the area, directly down-glacier of striated, stoss surfaces. The andesite bedrock in the study area is lava that erupted $\sim 100000$ years ago $(\mathrm{ka})$ based on whole-rock K-Ar (Lescinsky and Sisson, 1998). Since the lava was emplaced, it has been largely covered by Paradise Glacier. The sample described herein and the one previously reported (Hallet, 1975) were both collected within the area covered by ice during the Little Ice Age (LIA).

The sample reported herein includes both lee and stoss surfaces of a decimeter-scale bedrock undulation (Figs 2c, d). Cross-sections $(40 \times 20 \mathrm{~mm})$ were cut perpendicular to the glacially abraded surface, and polished thin sections were prepared both parallel and perpendicular to the former glacier sliding direction inferred from distinct striations (Fig. S2). The general structure and mineralogy were studied using an optical microscope and imaged with Leica CCD color camera (DFC 310 FX) using a monocular (Leica Z16 APO A MacroFluo fluorescent).

Further, high-resolution imaging and major element analyses of the thin sections were conducted using an electron probe micro analyzer (EPMA, JEOL Superprobe JXA-8230) equipped with energy-dispersive $\mathrm{x}$-ray spectroscopy (EDS) and wavelengthdispersive spectrometers (WDS) detectors, in the Hebrew University of Jerusalem. We use the EPMA to produce a WDS line profile of 371 points, $5 \mu \mathrm{m}$ apart, with the following conditions: electron beam of $0.2 \mu \mathrm{m}$ spot size, set to $15 \mathrm{kV}$, and 15 $\mathrm{nA}$. In addition to the line profile, we perform WDS elemental maps (pixel size of $1 \mu \mathrm{m}$ ) under the following conditions: electron beam set to $15 \mathrm{kV}$ and $50 \mathrm{nA}$, dwell time of $50 \mathrm{~ms}$, and background is consistent with the results of an additional line profile cut through the map area. Data were processed with a Phi Rho Z (PRZ) correction procedure. The data were calibrated against silicate and oxide standards (natural minerals - SPI 53). The detection limit for the WDS measurements is $40-100 \mathrm{ppm}$ with a maximum error of $1 \%$ of the measured concentrations.
Therefore, to measure trace elements with lower concentrations, a different method should be applied.

In situ measurements of trace elements ( $\mathrm{U}$ and $\mathrm{Th}$ ) and U-series isotopic analyses were obtained using the sensitive high-resolution ion microprobe with reverse geometry (SHRIMP-RG) co-operated by the USGS and Stanford University (Coble and others, 2018). This method is fully described in the Supplementary material. To investigate the submicron scale near-surface of the stoss side of the sample, foils of cross-sections extending down into the rock were prepared with a focused ion beam (FIB, Dual Beam Helios 460) and imaged using high-resolution transmission electron microscopy (HRTEM, Themis 60-300).

\section{Observations}

\subsection{Field observations}

In the study area, the surface of glacially eroded andesite shows systematic color differences from dark grey striated stoss surfaces (the bedrock color) to rougher, light-colored, surface along shallow, tens $\mathrm{mm}$-scale depressions at the lee of small bedrock protuberances where subglacial deposits coat the bedrock (Figs 2b-d). The deposits generally occur on the upper part of the depressions, close to the break in slope at the crest of the resulting bed protuberance. Rarely, if ever, do the deposits extend along the mid- or lower portion of the exposed depression. On the studied sample, the bedrock surface steepens down-glacier $\sim 20^{\circ}$ from stoss to lee sides; a break in slope (schematically illustrated by black line in Fig. 2d) marks the sharp transition from abraded bedrock to the lee surface, distinctly covered by the deposit that is up to $2 \mathrm{~mm}$-thick and is comprised of laminae tens to hundreds microns thick.

\subsection{Microscopic observations: lee side - layered deposit}

A cross-section through the lee side deposit, parallel to the sliding direction and perpendicular to the glacially eroded surface (Fig. 2d), shows the laminated structure that suggests distinct episodes of formation (Fig. 3). Two main types of laminae are visible in plane-polarized light: (1) light brown, relatively clear ones with few rock and mineral fragments; herein we refer to these as fragments, and to the intervening homogeneous material as matrix (2) darker, nearly opaque laminae, with abundant fragments (Fig. 3a). The laminae vary slightly in thickness over distances of several $\mathrm{mm}$ and can taper out within the deposit or end abruptly at the surface where erosion and weathering have removed a portion of the deposit (Figs 3a, b).

Back-scattered electron images reveal the distinct chemistry and fragment content of the laminae (Fig. 3b). The variation in major element chemistry (presented as oxides: $\mathrm{SiO}_{2}, \mathrm{CaO}$, $\mathrm{P}_{2} \mathrm{O}_{5}, \mathrm{Al}_{2} \mathrm{O}_{3}, \mathrm{Na}_{2} \mathrm{O}$ and $\mathrm{K}_{2} \mathrm{O}$ ) across the laminae was characterized using WDS element maps (Figs 3d, e and Fig. S3). A profile across the thickest section of the deposit suggests a negative correlation between several major elements (Fig. $3 \mathrm{c}$ and Fig. S4), such as $\mathrm{SiO}_{2}$ and $\mathrm{CaO}$. Whereas the matrix of Si-rich laminae is highsilica $\left(\mathrm{SiO}_{2}>85 \%\right)$ and depleted in calcium and phosphorus (Fig. 3e); the Ca-rich laminae is relatively depleted in silicon but enriched in phosphorus. The compositions of all layers differ sharply from the bulk composition of the andesite bedrock, which is relatively low in $\mathrm{CaO}(<5 \mathrm{wt} \%)$ and $\mathrm{P}_{2} \mathrm{O}_{5}(<1 \mathrm{wt} \%)$, and high in $\mathrm{Na}$ and $\mathrm{K}$ (Fig. S3).

\subsection{Microscopic observations: stoss side - a thin coating covers the extremely smooth abraded surface}

On the stoss side, no deposits are visible on the specimen or in optical microscope sections across the surface (Fig. S2a). 

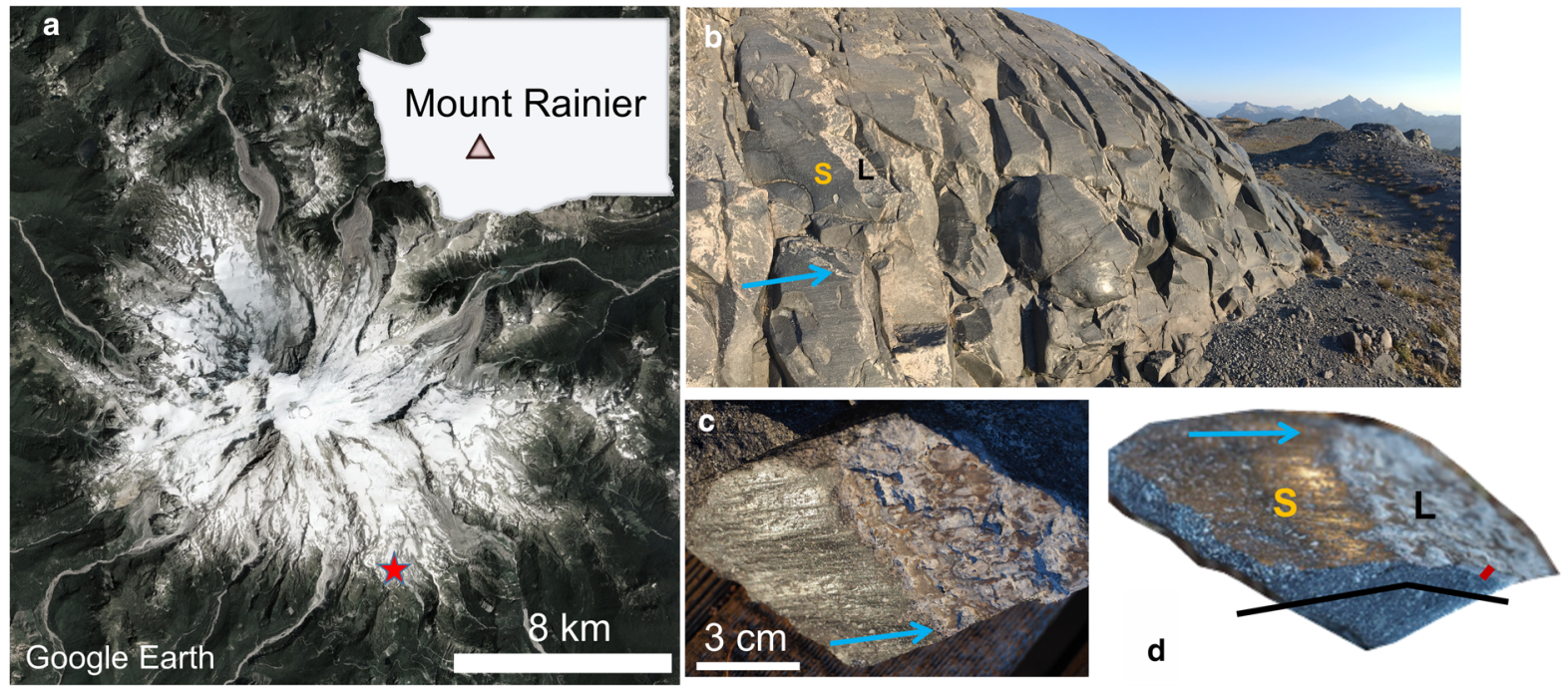

Fig. 2. (a) Study area (red star $\mathrm{N} 46.801^{\circ}, \mathrm{W} 121.715^{\circ}$; north is up). (b) Looking south-east, in the general direction former glacier flow (blue arrow), on a glacially eroded $\sim 4 \mathrm{~m}$-high bedrock ridge. The striated and polished andesite surface on the stoss (S) side of local highs glistens and is darker than the light-toned deposits on lee (L) sides. (c) Top view close-up of the study sample. Left side is the striated surface; right side is the step-like surface of the grey deposit. (d) Oblique view of the same sample. The break in slope at the stoss-lee transition is shown schematically by a black line in front of one of the saw cuts. The red mark represents the 2 mm-thickness of the deposit exposed at the cut.

However, two orthogonal foils (ultra-thin sections) cut perpendicular to the polished surface using FIB and imaged by transmission electron microscopy (TEM) reveal sub-micron structures as well as a coating on the bedrock (Fig. 4).

The glacially abraded bedrock surface on the stoss side results from sharp mechanical truncation across individual mineral grains and the microcrystalline groundmass. At the foil-scale $(\sim 1 \mu \mathrm{m})$, the surface looks perfectly planar (Figs $4 \mathrm{a}, \mathrm{b})$, even in the section perpendicular to former ice sliding direction, despite differences in the mechanical properties of the andesine and groundmass and the presence of clear striations (grooves) on the andesite bedrock (Fig. 2c). Moreover, the surface of the thin coating is slightly rougher than its base, the abraded bedrock surface, contrary to the subglacial coating on abraded granitic bedrock in the Sierra Nevada (Siman-Tov and others, 2017).

Parallel, transverse micron-size cracks damage the bedrock surface but do not extend into or cut through the thin coating. These cracks, hundreds of nanometers-long, seen in the foil cut parallel to the glacier sliding direction (Fig. 4a), dip from the surface $60-70^{\circ}$ down-glacier, roughly parallel to the inferred maximum compressive stress exerted by ice-entrained debris sliding from right to left (Fig. 4a). Importantly, similar cracks were not observed in the foil cut perpendicular to the striations, consistent with their subglacial origin.

The tens of nanometer-thick coating extends continuously over the abraded andesite surface. Its thickness varies smoothly and reaches a maximum of $170 \mathrm{~nm}$, in the study section where it includes a large $(\sim 100 \mathrm{~nm})$ mineral fragment (Fig. $4 \mathrm{c})$. The matrix of the coating is chemically homogeneous, in contrast with the bedrock (Figs $4 \mathrm{~d}-\mathrm{f}$ ). The EDS results suggest that the coating is silica enriched, $\mathrm{SiO}_{2}>80 \mathrm{wt} \%$, and depleted in other major cations: $\mathrm{Al}_{2} \mathrm{O}_{3}<10 \mathrm{wt} \%, \mathrm{Na}_{2} \mathrm{O}$ and $\mathrm{CaO}<3 \mathrm{wt} \%$.

\subsection{Radiometric dating of the subglacial deposit}

The U-Th isotopic compositions of Ca-rich laminae were measured in situ using secondary ion mass spectrometry on the SHRIMP-RG. Measured isotopes include the radioactive parent ${ }^{238} \mathrm{U}$ as well as the short-lived intermediate daughter products ${ }^{234} \mathrm{U}$ and ${ }^{230} \mathrm{Th}$ (Cheng and others, 2000). Fractionation by both chemical and physical processes can produce enrichment or depletion of these intermediate daughter and resulting activity ratios above or below 'secular equilibrium'. Generally speaking, $\mathrm{U}$-Th dates applied to precipitates from waters exploit the fractionation in this decay chain due to the insolubility of thorium in waters and thus the exclusions of ${ }^{230} \mathrm{Th}$ from precipitate upon formation. A date is calculated from the magnitude of ${ }^{230} \mathrm{Th}$ ingrowth. Although not a member of the ${ }^{238} \mathrm{U}$ decay chain, ${ }^{232}$ Th was measured to monitor detrital contamination that would contribute to excess ${ }^{230} \mathrm{Th}$. Again, generally speaking minerals that form from waters will have low ${ }^{232} \mathrm{Th} /{ }^{238} \mathrm{U}$ compositions, reflecting the insolubility of thorium. Measurements with $\left({ }^{230} \mathrm{Th} /{ }^{232} \mathrm{Th}\right)>15$, where parentheses denote activity ratios, reflect ${ }^{230} \mathrm{Th}$ contribution from $\mathrm{U}$-decay and effectively rule out the effects of ${ }^{230} \mathrm{Th}$ addition from silicates.

We targeted thick laminae (thicker than the spot size diameter $\sim 35 \mu \mathrm{m}$ ) that were free of lithic fragments (Fig. S5 and Table S1). The Ca-rich laminae that formed beneath the Paradise Glacier are strongly enriched in uranium $(\sim 2-50 \mathrm{ppm})$, and thus provide an opportunity to assess both the age of these deposits and geochemical setting in which they form. The $\left({ }^{234} \mathrm{U} /{ }^{238} \mathrm{U}\right)$ composition is 150-500\% above secular equilibrium. This enrichment results from the physical ejection of ${ }^{234} \mathrm{U}$ into waters from the decay of ${ }^{238} \mathrm{U}$ housed in silicates and is commonly observed in subglacial waters and/or the precipitates that form from such waters (Blackburn and others, 2019, 2020 and references therein). The $\left({ }^{230} \mathrm{Th} /{ }^{238} \mathrm{U}\right)$ values are $10-60 \%$ below secular equilibrium likely due to the insolubility of ${ }^{230} \mathrm{Th}$ in waters and consistent with the Ca-rich laminae forming from fluids. This isotopic disequilibrium suggests a range of ages from $\sim 10$ to $30 \mathrm{ka}$, but are clustered $\sim 20 \mathrm{ka}$ (Fig. 5). Although multiple laminae were analyzed, only one lamina had $\mathrm{U}$ concentrations sufficiently high to yield ${ }^{230} \mathrm{Th}$ above background levels. Therefore, we were unable to distinguish different ages on different laminae within analytical uncertainty.

\section{Discussion}

\subsection{Lee side: layered deposit}

High-resolution elemental maps (Figs 3d, e) show that the siliceous lee deposit is laminated with individual lamina having distinct rock-fragment abundance and matrix composition. The 

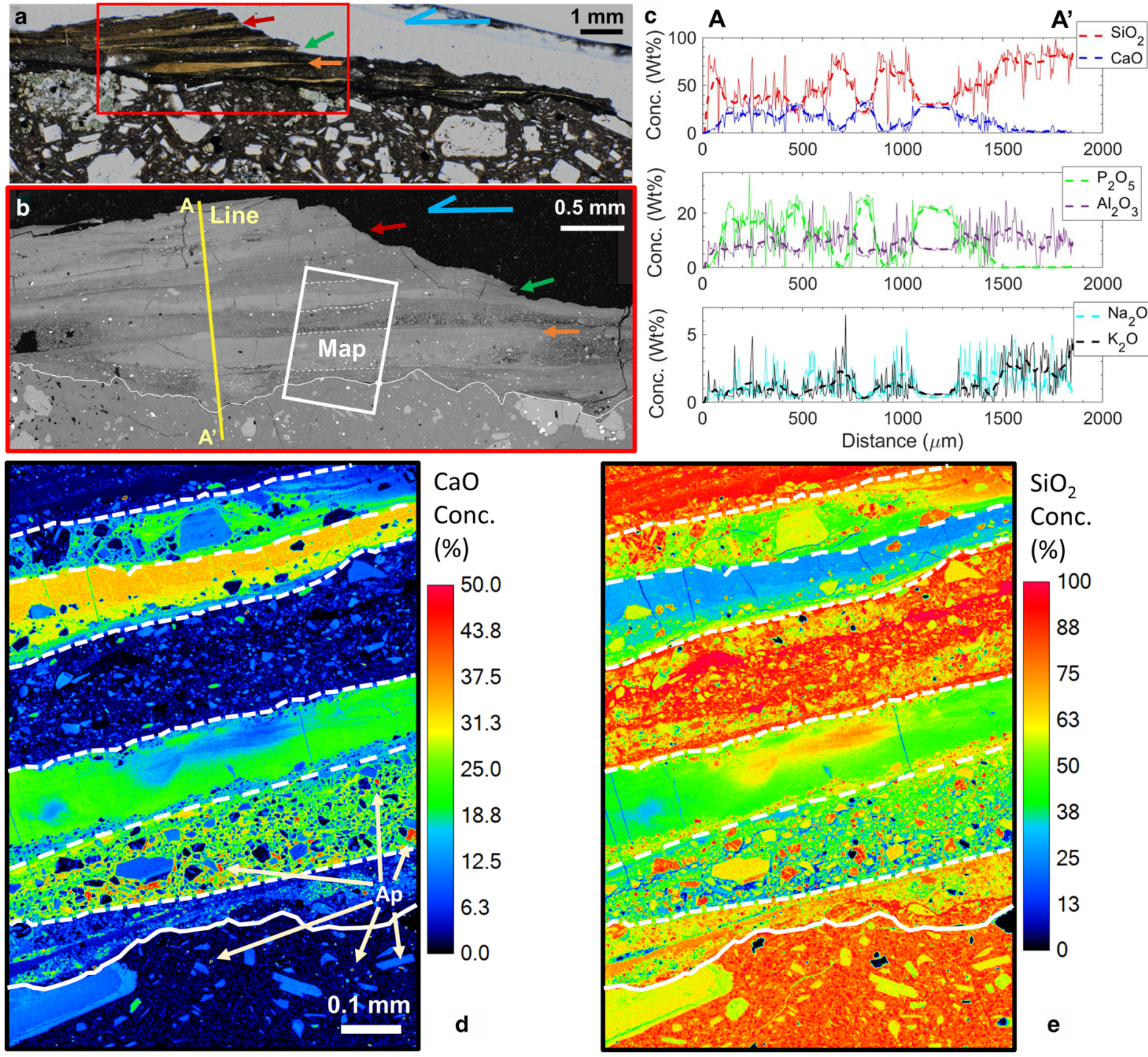

Fig. 3. Lee side subglacial deposit. (a) Thin section of the deposit and underlying andesite bedrock in transmitted light micrograph, along the former glacier sliding direction, from right to left (blue arrow). The upper laminae of the deposit are truncated on the up-glacier side. Light colored laminae are relatively free of rock fragments, whereas darker ones contain many fragments. (b) Back-scattered electron image of a portion of panel a (red rectangle). Ca-rich laminae are marked by short arrows. Brighter areas are generally richer in elements with higher atomic numbers. Locations of the compositional profiles (panel c) and maps (panels d-e) are marked by a line and a rectangle, respectively. The glacially eroded bedrock underlying the deposit is marked by white line. (c) Element profile, expressed as oxide concentration, from A to A' shows that Si-rich laminae are depleted in $\mathrm{Ca}$ and $\mathrm{P}$ while $\mathrm{Ca}$-rich laminae are depleted in $\mathrm{Si}$, Al, $\mathrm{Na}$ and $\mathrm{K}$. The original data (solid line) are smoothed using a 15-point moving average (dashed line). Note the distinct vertical scale for each sub-panel. (d) Ca map suggests that the thickest fragment-free laminae are Ca-rich. Arrows point to red fragments provisionally labeled 'Ap' for apatite, in view of their high $\mathrm{CaO}$ and $\mathrm{P}_{2} \mathrm{O}_{5}$ concentrations (Fig. S3). (e) The matrix of Si-rich laminae is $>85 \mathrm{wt} \%$. White, dashed lines delineate seven prominent layers in the deposit with distinct chemical composition and fragment concentration. Note the distinct value range in the color bar for each panel ( $\mathrm{d}$ and e). These panels are also shown using colored grayscale maps in Figure S3.

deposit is a complex depositional feature modified by subsequent weathering and erosion similar in form to coatings of calcitecemented clay- to sand-sized lithic grains that formed under Mendenhall Glacier, Alaska, USA (Carter and others, 2003). The rough weathered surface of the deposit and, in particular, its sharp exposed edges are more consistent with differential dissolution than mechanical abrasion (Figs 3a, b, green arrow).

The siliceous deposit requires chemical exchange between water and the bedrock; mechanical crushing and densification of wear material alone are not sufficient. The existence of a relatively uniform matrix deposit devoid of rock or mineral fragments, and the compositional differences between the matrix and the underlying bedrock indicate that chemical processes are essential for the deposit to form. The measured phosphorus and calcium oxide concentrations, for example, are low in the underlying andesite bedrock $\left(\mathrm{CaO} \sim 6 \%\right.$ and $\mathrm{P}_{2} \mathrm{O}_{5} \sim 0.3 \mathrm{wt} \%$ according to Sisson and others, 2014), and distinctly higher in the deposit, reaching $\sim 35$ and $\sim 25 \mathrm{wt} \%$, respectively. Similarly, $\mathrm{K}$ and $\mathrm{Na}$ are almost absent from the deposit but relatively abundant in the host rock groundmass (Figs S3c, d).

Insights into potential formative processes can be gleaned from extensive research on the better developed subglacial carbonate deposits. As noted in the introduction, considerable field and geochemical evidence from glaciated carbonate terrains suggests that subglacial chemical activity is driven by ice sliding past small protuberances in the glacier bed (e.g. Ng and Hallet, 2002) with water flow, freezing/melting, cryo-concentration occurring in a microscopic water film at the ice-bedrock interface along particular portions of the glacier bed (Fig. 1). On stoss surfaces, ice melts producing chemically aggressive water that dissolves the bed. The regelation (refreezing) of this water on the lee side elevates its solute concentration to the point that $\mathrm{CaCO}_{3}$ precipitates due to the solute exclusion by ice growth. This scenario accounts for the morphology, mineralogy and geochemistry of the 


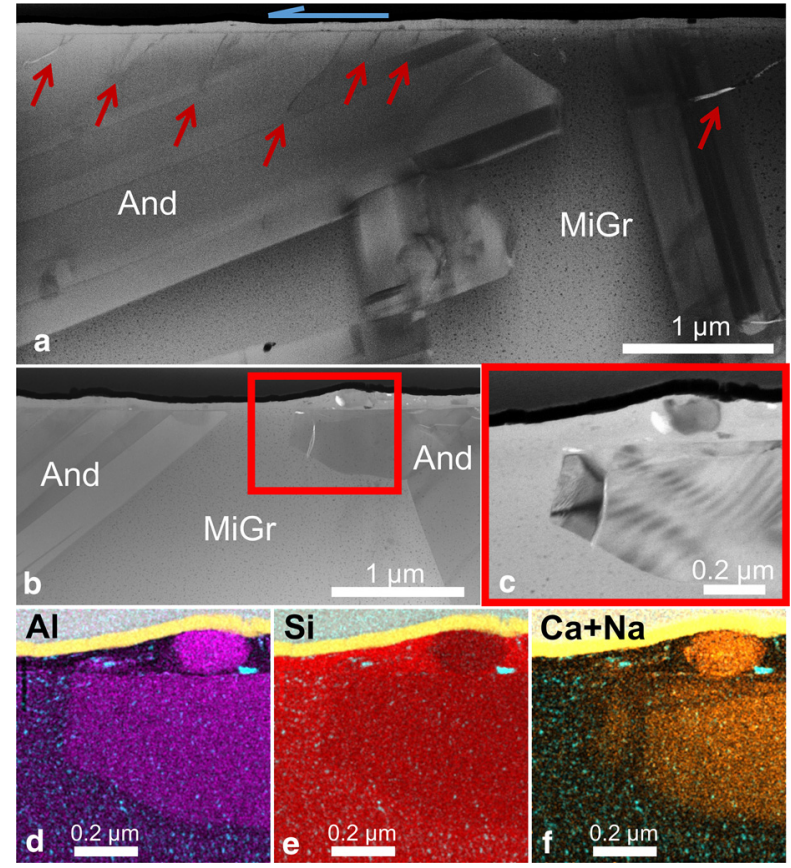

Fig. 4. Stoss side abraded surface, coating and bedrock. (a) A bright field, TEM image of an ultra-thin section parallel to the former glacier sliding direction (to the left, blue arrow). This section of andesite lava shows twinned andesine ('And') feldspar phenocrysts and the lava microcrystalline groundmass ('MiGr'). A thin coating is visible between the bedrock and the artificial Au-Pt coatings (in black). The bedrock surface is extremely smooth. Transverse sub-parallel fractures, steeply-dipping down-glacier, extend from the abraded surface (below the coating) into the bedrock (red arrows). (b) A foil cut perpendicular to the former glacier sliding direction. Small fragments embedded within the coating thicken it locally, making the coating surface roughe than the abraded bedrock surface. (c) Zooming in to the area marked by a red rectangle in $b(d)$ through ( $f$ ). Element maps of the region shown in $\mathrm{c}$ for, (d) aluminium (purple); (e) silicon (red); and (f) sodium and calcium (orange). In each map, color brightness increases with concentration; blue is iron, the top yellow band is the gold coating and above it the platinum coating.

subglacial $\mathrm{CaCO}_{3}$ precipitates, as well as observed spatial pattern of dissolution and precipitation that is tightly linked to the topographic details of the glacier bed (Hubbard and Hubbard, 1998). We expect similar scenarios in silicate and other bedrock areas, and that they account for the diverse characteristics of the siliceous subglacial deposit. Moreover, we are not aware of any other mechanism for reaching supersaturation at the bed of temperate glaciers, a setting continuously bathed and flushed with essentially pure, $0^{\circ} \mathrm{C}$ meltwater. Common mechanisms leading to mineral precipitation are unlikely in this subglacial setting; the general abundance of $0^{\circ}$ $\mathrm{C}$ water at the glacier bed essentially eliminates the roles of both evaporation and cooling in causing precipitation.

The rock and mineral fragments in several of the laminae are noteworthy and quite unexpected in view of prevailing ideas about subglacial precipitation and glacier sliding with water flowing along a micron-thick regelation water film between the ice and bedrock (Nye, 1972). Not only are many fragments much larger than could theoretically pass through the microscopic basal water film, they can be closely packed with numerous fragments in direct contact with one another. In addition, their uniform spatial distribution in certain laminae, with no hint of settling, alignment or layering (Figs 3d, e), suggests a subglacial setting quite different from the common concept of a simple subglacial water film, much as previously noted (Carter and others, 2003). Instead of water flow, freezing and chemical exchange occurring in a uniform microscopic film between the ice and bedrock, these processes more likely occurred at sites of incipient separation between the ice and the glacier bed. Separation would allow lithic fragments considerably larger than the theoretical

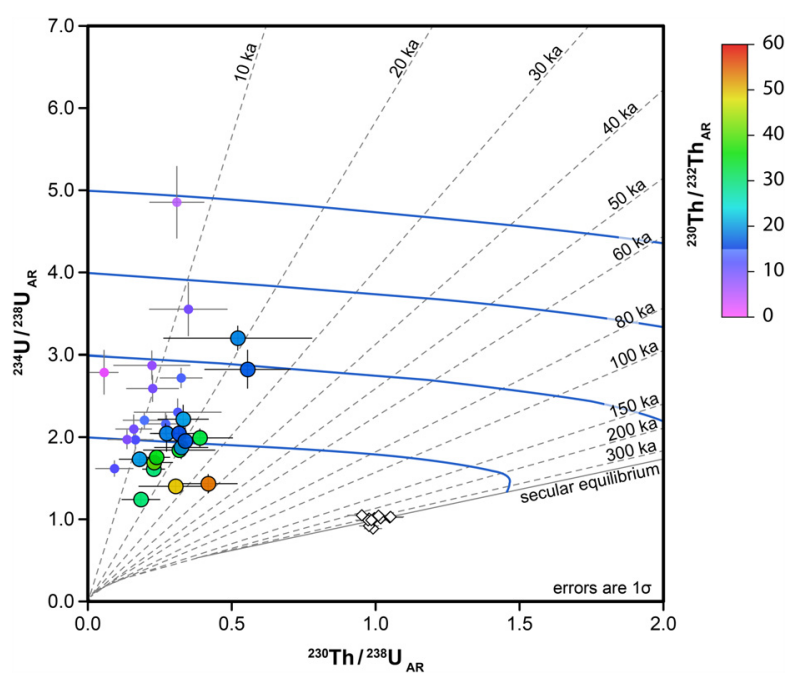

Fig. 5. U-Th isotope data for multiple spots $(N=29)$ measured by SHRIMP-RG on U-rich laminae of the lee side deposit. Error bars are $1 \sigma$; opal standards BZVV (Nevada, USA) are included (diamonds). The laminae, forming with a range of $\left({ }^{234} \mathrm{U} /{ }^{238} \mathrm{U}\right)$ initial values and no initial ${ }^{230} \mathrm{Th}$ (e.g. system starts along $Y$-axis), evolve to the right, as a result of ${ }^{230} \mathrm{Th}$ ingrowth, following the blue curves towards secular equilibrium (solid line). The measured spots of the lee deposit are color-coded by $\left.{ }^{(230} \mathrm{Th} /{ }^{232} \mathrm{Th}\right)$, with the most reliable measurements yield $\left({ }^{230} \mathrm{Th} /{ }^{232} \mathrm{Th}\right)>15$ (larger spots).

micron-film thickness to both be transported by the water at the ice-rock interface and to resist being entrained by sliding regelation ice. Moreover, rather than occurring in subglacial water, these processes may have occurred in a more viscous, deforming paste-like layer of fine-grained lithic fragments (glacial flour) saturated with water or, perhaps siliceous gel. Silica gels or amorphous nanopowders are known to form during low velocity $\left(10^{-8}-10^{-4} \mathrm{~m} \mathrm{~s}^{-1}\right)$ shear experiments of siliceous gouge material (Yund and others, 1990; Rowe and others, 2019). Other experimental studies suggested that the production of siliceous pastes is accompanied by a drop in the frictional strength (Goldsby and Tullis, 2002; Di Toro and others, 2004).

The matrix of the siliceous laminae is either Si-rich or Ca-rich, suggesting a corresponding dichotomy in the composition of subglacial water. The Si-rich laminae, $>85 \mathrm{wt} \%$ (Fig. $3 \mathrm{e}$ ), precipitated from subglacial waters super saturated in Si. Whereas the silica concentration of glacial run off of volcanic terranes tends to be relatively high (Keller and Reesman, 1963), it is far below Si saturation and requires $\mathrm{Si}$ enrichment to precipitate; subglacial solute exclusion due to regelation along lee surfaces provides a natural mechanism for the solute enrichment. The formation of amorphous silica under Paradise Glacier is not surprising in view of recent work reporting amorphous silica from freezing solutions in the laboratory (Fig. 3 in Oelze and others, 2015) and opaline silica in similar glacial settings. The latter is based on visible to near-infrared reflectance spectra of rock outcrops and proglacial sediments in the Oregon Cascades (Rutledge and others, 2018).

On the other hand, the stoichiometry of Ca-rich laminae (oxides in wt\%: $35 \mathrm{CaO}, 24 \mathrm{SiO}_{2}, 25 \mathrm{P}_{2} \mathrm{O}_{5}$ and $6 \mathrm{Al}_{2} \mathrm{O}_{3}$ ) is puzzling as it differs markedly from that of the bedrock (oxides in wt\%: 6 $\mathrm{CaO}, 62 \mathrm{SiO}_{2}, 0.3 \mathrm{P}_{2} \mathrm{O}_{5}$ and $17 \mathrm{Al}_{2} \mathrm{O}_{3}$ from Table 1 of Sisson and others, 2014), pointing to considerable selective chemical enrichment and precipitation of $\mathrm{Ca}$ - and P-rich laminae. Moreover, this stoichiometry does not correspond to any known mineral, which is consistent with its amorphous or poorly crystalline nature (Hallet, 1975).

\subsection{Stoss side coating}

Cryo-concentration driven by glacier sliding readily accounts for subglacial chemical deposits along lee surfaces where the ice 
pressure drops and meltwater continuously refreezes (Fig. 1). In contrast, the formation of chemical coatings on stoss surfaces where pressure melting occurs is unexpected. Melting produces chemically aggressive water because the solute content of basal ice is generally extremely low. Dissolution furrows common on stoss surfaces of carbonate bedrock clearly attest to the water being undersaturated along these surfaces (e.g. $\mathrm{Ng}$ and Hallet, 2002). In this context, the thin striated carbonate coatings on stoss surfaces reported by Carter and others (2003) at Mendenhall Glacier are noteworthy because they seem to constitute a counter example. They may, however, be the product of sequential abrasion and precipitation under the terminus of a glacier where complex dynamics of ice flow and calving into a terminal lake can significantly complicate the direction of ice flow, local subglacial hydrology, and the position and extent of cavities. These complexities are not expected at the Paradise Glacier study site, where the geometry of the stoss-lee sides on a specific bed protuberance is clear and the sliding direction is governed largely by the steep valley slope.

We suggest that the stoss side coating formed subaerially after glacial retreat much as it does in laboratory investigations of chemical weathering and reprecipitation in dilute aqueous solution contacting silicate minerals, and as varnish forms in diverse natural settings (e.g. Hellmann and others, 2012). We do not wish, however, to dismiss the possibility that they formed subglacially despite the significant cryo-dilution expected along stoss surfaces.

Stoss and lee side surfaces differ considerably in terms of surface roughness and chemical deposit thickness, but are quite similar chemically. In particular, $\mathrm{SiO}_{2}>80 \mathrm{wt} \%$ in the coating on the stoss side and $>85 \mathrm{wt} \%$ in the Si-rich laminae in the lee side deposit. For the stoss side, the very smooth and reflective bedrock surface (i.e. optically smooth) facing up-glacier, was likely formed by a sustained polishing process with very fine wear material. Surprisingly, the thin coating makes this surface rougher than the truncated bedrock surface (Fig. 4a), which is unexpected because coatings formed under shear usually tend to smooth surfaces (Siman-Tov and others, 2013, 2017). A set of transverse cracks dipping steeply down-glacier from the bedrock surface reflect elevated contact stresses, presumably formed by a passing larger rock fragment in forceful contact with the stoss side (Fig. 4a). The continuous nature of the coating over these cracks attests to the chronology of events, the cracks preceding the formation of the coating either subglacialy or subaerially.

\subsection{The temporal evolution of subglacial deposits}

The U-Th dating results suggest that the deposit formed 10-30 ka. Here, we discuss the underlying data and their reliability. Because thorium is insoluble in water, water-lain precipitates usually form in the absence of the daughter product, ${ }^{230} \mathrm{Th}$, allowing an age to be determined from its amount. In addition to this ${ }^{230} \mathrm{Th}$ sourced from the decay of ${ }^{234} \mathrm{U}$, there is another source of ${ }^{230} \mathrm{Th}$ in these samples: 'initial' ${ }^{230} \mathrm{Th}$ most likely derived from silicates or organic contamination in the precipitates. We can monitor this second, contamination source by measuring ${ }^{232} \mathrm{Th}$, which is not a part of the U-decay chain. Both the $\left({ }^{230} \mathrm{Th} /{ }^{232} \mathrm{Th}\right)$ and $\mathrm{Th} / \mathrm{U}$ can serve as the index of the quality of a given age determination. A $\left({ }^{230} \mathrm{Th} /{ }^{232} \mathrm{Th}\right)$ greater than $\sim 15$ points to a dominance of ${ }^{230} \mathrm{Th}$ by uranium decay and to any uncertainty in the source of ${ }^{230} \mathrm{Th}$ (U-decay or detrital) having little-to-no bearing on the age calculation. For analyses where the precipitates include silicate fragments or organic material, which tend to have increased thorium, we expect the ${ }^{230} \mathrm{Th}$ to be elevated and yield inaccurately older apparent age (as ${ }^{230} \mathrm{Th} /{ }^{238} \mathrm{U}$ values increase). Therefore, these impure spot analyses of Si-rich coating that incorporated trace amounts of rock fragments that comprised elevated amounts of ${ }^{232} \mathrm{Th}$ relative to $\mathrm{U}$ decay products $\left({ }^{230} \mathrm{Th}\right)$ tend to have $\left({ }^{230} \mathrm{Th} /{ }^{232} \mathrm{Th}\right)<15$; they are assumed to be less reliable. Using only spots yielding $\left({ }^{230} \mathrm{Th} /{ }^{232} \mathrm{Th}\right)>15$ correlates with age $\sim 20 \mathrm{ka}$ (Fig. 5), which we interpret to be the formation age of the subglacial deposit.

The deposit formation age (10-30 ka) suggests that the deposit formed during the Last Glacial Maximum (LGM) and have survived subsequent glacial erosion and subaerial weathering. This range of ages is substantially younger than the lava flow on the south eastern flank of Mount Rainier, dated by K-Ar techniques to 80-115 ka (Lescinsky and Sisson, 1998). Hallet (1975) suggested that the deposits were forming as recently as about 1850 $\mathrm{AD}$, when the study area was uncovered by the glacier at the end of the LIA. Experience with subglacial carbonate precipitates (Hallet, 1976) that disappear within decades of exposure by ice retreat led him to assume that the thin subglacial silica deposits on Mt. Rainier probably formed during the last major glacial advance, because older deposits would have been destroyed by weathering or subsequent glacial abrasion. We now know that the suggestion and underlying assumptions were incorrect; the subglacial silica-rich deposits can survive subsequent glacial erosion and weathering far longer than formerly thought, consistent with other reports of older subglacial carbonate deposits in diverse settings including Antarctica (Aharon, 1988; Frisia and others, 2017), the Alps (Thomazo and others, 2017; Lipar and others, 2021) and northern Canada (Refsnider and others, 2012).

Since the LGM, when alpine glaciers in this and other regions were generally largest, the study site has likely been ice-free intermittently for much of the time except when glaciers were advancing and retreating on millennial timescales starting about $7.5 \mathrm{ka}$ (Samolczyk, 2011). Subglacial silica deposition and glacial erosion likely resumed during these more recent advances because the study site is close enough to the current terminus of Paradise Glacier that even, with minor increases in climatic conditions favoring ice accumulation, the glacier would cover the study area. It did as recently as the middle of last century.

\subsection{Variations in subglacial hydrology recorded by lee-side deposits}

The varying chemical composition of the lee-side laminae implies alternating subglacial aqueous chemistries. Active sliding and abrasion likely enhance chemical weathering by creating large areas of fresh reactive surfaces on particles comminuted by abrasion and on the micro-fractured bedrock, and by bathing these mineral surfaces in continuously replenished fresh meltwater. Abrasion may also accelerate the chemical weathering of silica by elevating the $\mathrm{pH}$ significantly, thereby greatly increasing the solubility of $\mathrm{SiO}_{2}$ (Keller and Reesman, 1963). Subglacial freezing later concentrates the $\mathrm{SiO}_{2}$ and other solutes, which then precipitate as amorphous material where and when the basal water exceeds saturation.

The siliceous Ca-rich laminae likely form from subglacial waters with particularly high $\mathrm{Ca}$ concentrations and/or high $\mathrm{pH}$. We speculate that changes in subglacial hydrology affect the chemical composition of water at the glacier bed and that this water originates from meltwater chemically similar to local outlet streams. Keller and Reesman (1963) reported the following concentrations - Si, K, Na, Ca, Mg: 4.28, 0.57, 1.54, 2.07, 0.74 ppms - for 'glacial milk' collected in an outlet stream from the nearby Nisqually Glacier. The relative abundance of $\mathrm{Ca}$, only exceeded by $\mathrm{Si}$, helps account for the formation of the siliceous Ca-rich laminae. Moreover, precipitation of the most common phase, $\mathrm{Si}$, in the Si-rich laminae would increase the $\mathrm{Ca} / \mathrm{Si}$ ratio in the residual subglacial water, contributing to the relative $\mathrm{Ca}$ 
enrichment and formation of the Ca-rich laminae. The cause of abundant phosphorous in that layer is not clear, but is consistent with the recent recognition that glaciers, at least in Greenland, are major sources of phosphorous (Hawkings and others, 2016). It would also be consistent with local sources of P-rich water at the glacier bed, such as warm spring waters and similar sources that remain concealed or undiscovered (Sisson, T. written communication, 2020). Such sources would contrast in P-concentration with many springs and streams in the Cascade Range of western North America that are near or below the limit-of-detection.

The sharp boundaries between laminae with distinct elemental compositions suggest abrupt changes in subglacial chemical conditions, as well as discontinuities formed by erosion, either abrasion or dissolution. Moreover, the laminae (Figs 3d, e) change laterally on mm-scale in terms of layer thickness, fragment content and chemical composition. Lee regions may be controlled by two distinct hydrological regimes: local water flow in a micron-thick film separating the ice from the bed governed by regelation processes; and water flow through larger subglacial conduits (Fig. 1). For both cases, water originates from melting and is relatively pure, much like glacial ice; it dissolves silica, other ions and entrains rock fragments released by melting ice or entrained from the glacier bed. In the subglacial film, solutes are concentrated where water freezes. However, two end-member flow systems involving regelation and cryo-concentration can be envisioned (Fig. 1): (1) a closed system, in which all of the water that is continuously produced by pressure melting along stoss surfaces flows to adjacent lee surfaces and refreezes there, locally causing high solute concentrations; (2) an open system in which the water from pressure melting mixes with water from the broader subglacial network of cavities and conduits that accomodate meltwater generally derived from the glacier surface before reaching lee regions. The mixing and larger throughput of fresh meltwater are generally conducive to more dilute and chemically aggressive waters at the glacier bed. The substantial variations in matrix chemistry of the siliceous deposit documented herein likely reflect variations or switches between these end members driven by seasonal or longer period changes of the subglacial hydrologic system. Surprisingly, based on classical theory for sliding over sinusoidal bed undulations (Nye, 1972) in the absence of cavities and conduits at the glacier bed, the thickness of the subglacial water film is independent of both position on the bed and the rate of glacier sliding. Hence, temporal variations in sliding are unlikely to readily account for the observed inter-laminae variation in lithic fragment size, but could well impact the deposit chemistry by varying the flux and mixing of water contacting the glacier bed. The information encoded in the microstratigraphy of the siliceous subglacial deposit is not currently well understood. Additional sampling and analyses in numerous sites would help in this regard by enabling differentiation between local and regional effects.

\subsection{Implications of subglacial silica-rich deposits}

Interest in subglacial silica-rich deposits has recently broadened considerably beyond a narrow subfield of glaciology. The detailed study presented herein may ultimately help understand the roles of cryospheric processes in much broader systems on Earth (e.g. Torres and others, 2017) and beyond. For example, Hawkings and others (2017) suggested that ice masses are more important for the global silicon cycle than previously appreciated. They noted, in particular, that ice sheets deliver downstream substantial fluxes of bio-essential nutrients (so-called 'nutrient factories') such as iron, phosphorus and nitrogen, mainly in reactive particulate form. Furthermore, they suggested that the dissolved flux and amorphous silica is $\sim 50 \%$ of the input from Arctic rivers, which may have significance for marine ecosystems because of the relatively high solubility of amorphous silica in seawater. This type of study highlights the potential value of detailed information recorded in amorphous siliceous subglacial deposits.

Moreover, this information may also bear on extra-terrestrial systems. Notably, subglacial deposits share characteristics with bedrock and other surfaces on Mars that commonly feature secondary silica and a significant amorphous component based on satellite and, more recently, rover observations in Gale Crater. Their origins, however, are not well understood (e.g. Mustard and others, 2008; Ehlmann and Edwards, 2014; Rutledge and others, 2018). The spectroscopic similarities between rock surfaces at Gale Crater and de-glaciated volcanic areas on Earth were recently reported by Rutledge and others (2018); they studied silica dissolution and precipitation at a glaciated volcano in the Oregon Cascades, similar to Mt. Rainier, as a Mars analog site. They report clear spectroscopic expressions of hydrated and opaline silica on glacial outwash, and Smith and others (2019) noted the similarity in the composition of the overall bulk amorphous component between Martian rocks and their glacial and paleosol samples.

\section{Conclusions}

New detailed analyses of a subglacial siliceous deposit at the lee of a bed protuberance on glacially eroded andesite bedrock provide an instructive glimpse at processes occurring at the glacier bed. The thin deposit consists of alternating $\mathrm{Ca}$ - and Si-rich laminae, with varying abundance of lithic fragments. The layering suggests recurring distinct changes in chemical and mechanical processes at the glacier bed and, perhaps, in the patchy occurrence of wet glacial flour or a debris-rich silica slurry between the ice and the glacier bed. U-Th analysis of the Ca-rich laminae suggests that the deposit formed 10-30 ka, during the LGM, earlier than previously assumed. We suggest that the lee-side deposit can be readily accounted for by cryo-concentration driven by regelation and glacier sliding. Close examination, down to the nanoscale, of the up-glacier side of the bed protuberance revealed a $\sim 100$ $\mathrm{nm}$ thick Si-rich coating on a perfectly smooth bedrock surface fractured by the local stresses developed during abrasion. We conclude that the stoss side coating probably formed subaerially, although we cannot rule out its formation subglacially. These observations illuminate potential chemical fingerprints of glaciers on diverse systems, ranging from the world's oceans to the rock surfaces seen on Mars, as well as fundamental aspects of subglacial hydrology and glacier sliding, a principal component of the motion of ice masses that continues to challenge glaciologists.

Supplementary material. The supplementary material for this article can be found at https://doi.org/10.1017/jog.2021.42.

Acknowledgements. We thank I. Popov, A. Vakahi, S. Remennik, from the center for nanoscience and nanotechnology, and Y. Levenson and O. Dvir from the EPMA lab, the Hebrew University of Jerusalem, for generous electron microscopy assistance. Thanks to H. Hauzer and J. Erez for use of microscopy facilities, and T. Sisson (USGS) for a wealth of information about the chemistry of streams, springs and bedrock in the study region. We also thank the editors Ralf Greve and Matthew Siegfried, and three anonymous reviewers for their detailed and constructive comments. This work was supported by the Gordon and Betty Moore Foundation (GBMF3289 to EEB), and NSF EAR-1624657.

\section{References}

Aharon P (1988) Oxygen, carbon and U-series isotopes of aragonites from Vestfold Hills, Antarctica: clues to geochemical processes in subglacial environments. Geochimica et Cosmochimica Acta 52(9), 2321-2331. doi:10.1016/0016-7037(88)90134-2. 
Blackburn T and 5 others (2019) Composition and formation age of amorphous silica coating glacially polished surfaces. Geology 47(4), 347-350. doi:10. 1130/G45737.1.

Blackburn T and 9 others (2020) Ice retreat in Wilkes Basin of East Antarctica during a warm interglacial. Nature 583, 554-559. doi:https:// doi.org/10.1038/s41586-020-2484-5.

Carter CL, Dethier DP and Newton RL (2003) Subglacial environment inferred from bedrock-coating siltskins, Mendenhall Glacier, Alaska, U.S.A. Journal of Glaciology 49(167), 568-576. doi:10.3189/172756503781830412.

Cheng $\mathbf{H}$ and 5 others (2000) The half-lives of uranium-234 and thorium-230. Chemical Geology 169(1-2(2000)), 17-33. doi:10.1016/S0009-2541(99)00157-6.

Coble MA and 7 others (2018) Trace element characterisation of MAD-559 zircon reference material for ion microprobe analysis. Geostandards and Geoanalytical Research 42(4), 481-497. doi:10.1111/ggr.12238.

Di Toro G, Goldsby DL and Tullis TE (2004) Friction falls towards zero in quartz rock as slip velocity approaches seismic rates. Nature 427, 436439. doi:https://doi.org/10.1038/nature02249.

Ehlmann BL and Edwards CS (2014) Mineralogy of the Martian surface. Annual Review of Earth and Planetary Sciences 42(1), 291-315. doi:10. 1146/annurev-earth-060313-055024.

Ford DC, Fuller PG and Drake JJ (1970) Calcite precipitates at the soles of temperate glaciers. Nature 226(5244), 441-442. doi:10.1038/226441a0.

Frisia S and 10 others (2017) The influence of Antarctic subglacial volcanism on the global iron cycle during the Last Glacial Maximum. Nature Communications 8, 15425. doi:10.1038/ncomms15425.

Goldsby DL and Tullis TE (2002) Low frictional strength of quartz rocks at subseismic slip rates. Geophysical Research Letters 29(17), 1844. doi:10. 1029/2002GL015240.

Hallet B (1975) Subglacial silica deposits. Nature 254(5502), 682-683. doi:10. $1038 / 254682 \mathrm{a} 0$

Hallet B (1976) Deposits formed by subglacial precipitation of CaCO3. Bulletin of the Geological Society of America 87(7), 1003-1015. doi:10. 1130/0016-7606(1976)87<1003:DFBSPO>2.0.CO;2.

Hawkings J and 9 others (2016) The Greenland Ice Sheet as a hot spot of phosphorus weathering and export in the Arctic. Global Biogeochemical Cycles 30(2), 191-210. doi:10.1002/2015GB005237.

Hawkings JR and 7 others (2017) Ice sheets as a missing source of silica to the polar oceans. Nature Communications 8, 14198. doi:10.1038/ncomms14198.

Hawkings JR and 14 others (2018) The silicon cycle impacted by past ice sheets. Nature Communications 9, 3210. doi:10.1038/s41467-018-05689-1.

Hellmann R and 8 others (2012) Unifying natural and laboratory chemical weathering with interfacial dissolution-reprecipitation: a study based on the nanometer-scale chemistry of fluid-silicate interfaces. Chemical Geology 294-295, 203-216. doi:10.1016/j.chemgeo.2011.12.002.

Hubbard B and Hubbard A (1998) Bedrock surface roughness and the distribution of subglacially precipitated carbonate deposits: implications for formation at Glacier de Tsanfleuron, Switzerland. Earth Surface Processes and Landforms 23(3), 261-270. doi:10.1002/(SICI)1096-9837(199803)23:3<261:: AID-ESP848>3.0.CO;2-5.

Keller WD and Reesman AL (1963) Glacial milks and their laboratorysimulated counterparts. Bulletin of the Geological Society of America 74 (1), 61-76. doi:10.1130/0016-7606(1963)74[61:GMATLC]2.0.CO;2.

Lescinsky DT and Sisson TW (1998) Ridge-forming, ice-bounded lava flows at Mount Rainier, Washington. Geology 26(4), 351-354. doi:10.1130/ 0091-7613(1998)026<0351:RFIBLF>2.3.CO;2.

Lipar M and 10 others (2021) Subglacial carbonate deposits as a potential proxy for a glacier's former presence. The Cryosphere 15(1), 17-30. doi: https://doi.org/10.5194/tc-15-17-2021.
Liu GN, Luo RS, Cao J and Cui ZJ (2005) Processes and environmental significance of the subglacial chemical deposits in Tianshan Mountains. Science in China Series D-Earth Sciences 48(9), 1470-1478. doi:10.1360/02yd0459.

Mustard JF and 35 others (2008) Hydrated silicate minerals on Mars observed by the Mars Reconnaissance Orbiter CRISM instrument. Nature 454(7202), 305-309. doi:10.1038/nature07097.

Ng F and Hallet B (2002) Patterning mechanisms in subglacial carbonate dissolution and deposition. Journal of Glaciology 48(162), 386-400. doi:10. 3189/172756502781831214.

Nye JF (1972) Water at the bed of a glacier. International Glaciological Society: Symposium on the hydrology of glaciers. pp. 189-194.

Oelze M, von Blanckenburg F, Bouchez J, Hoellen D and Dietzel M (2015) The effect of $\mathrm{Al}$ on $\mathrm{Si}$ isotope fractionation investigated by silica precipitation experiments. Chemical Geology 397, 94-105. doi:10.1016/j.chemgeo. 2015.01.002.

Refsnider KA and 5 others (2012) Subglacial carbonates constrain basal conditions and oxygen isotopic composition of the Laurentide Ice Sheet over Arctic Canada. Geology 40(2), 135-138. doi:10.1130/G32335.1.

Rowe CD and 7 others (2019) Earthquake lubrication and healing explained by amorphous nanosilica. Nature Communications 10(1), 320. doi:10.1038/ s41467-018-08238-y.

Rutledge AM and 5 others (2018) Silica dissolution and precipitation in glaciated volcanic environments and implications for Mars. Geophysical Research Letters 45(15), 7371-7381. doi:10.1029/2018GL078105.

Samolczyk M (2011) Late Pleistocene and Holocene Glacier Fluctuations in Mt. Rainier National Park, Washington, USA (Master thesis). University of Calgary, Alberta, Canada.doi:10.11575/PRISM/23187.

Sharp M, Tison JL and Fierens G (1990) Geochemistry of subglacial calcites: implications for the hydrology of the basal water film. Arctic, Antarctic, and Alpine Research 22(2), 141-152. doi:10.2307/1551299.

Siman-Tov S, Aharonov E, Sagy A and Emmanuel S (2013) Nanograins form carbonate fault mirrors. Geology 41(6), 703-706. doi:10.1130/G34087.1.

Siman-Tov S, Stock GM, Brodsky EE and White JC (2017) The coating layer of glacial polish. Geology 45(11), 987-990. doi:10.1130/G39281.1.

Sisson TW, Salters VJM and Larson PB (2014) Petrogenesis of Mount Rainier andesite: Magma flux and geologic controls on the contrasting differentiation styles at stratovolcanoes of the southern Washington Cascades. Bulletin of the Geological Society of America 126(1-2), 122-144. doi:10. 1130/B30852.1.

Smith RJ, Horgan B, McLennan SM and Achilles C (2019) Bulk compositions of X-ray amorphous materials in soils and sediments on Earth compared to X-ray amorphous materials in Gale Crater, Mars. Lunar and Planetary Science Conference. 2617 https://ui.adsabs.harvard.edu/abs/ 2019LPI....50.2617S.

Smith RJ, Rampe EB, Horgan BHN and Dehouck E (2018) Deriving amorphous component abundance and composition of rocks and sediments on earth and mars. Journal of Geophysical Research: Planets 123 (10), 2485-2505. doi:10.1029/2018JE005612.

Thomazo C and 6 others (2017) Geochemical processes leading to the precipitation of subglacial carbonate crusts at Bossons Glacier, Mont Blanc Massif (French Alps). Frontiers in Earth Science 5, 70. doi:10.3389/feart.2017.00070.

Torres MA, Moosdorf N, Hartmann J, Adkins JF and West AJ (2017) Glacial weathering, sulfide oxidation, and global carbon cycle feedbacks. Proceedings of the National Academy of Sciences of the USA 114(33), 8716-8721. doi:10.1073/pnas.1702953114.

Yund RA, Blanpied ML, Tullis TE and Weeks JD (1990) Amorphous material in high strain experimental fault gouges. Journal of Geophysical Research-Solid Earth 95(B10), 15589-15602. doi:10.1029/JB095iB10p15589. 